\title{
Evaluasi Penentuan Kawasan Lindung Kota Mataram dalam Perannya Sebagai Kawasan Peresapan Air
}

\author{
Humairo Saidah $^{1 *}$, Bambang Hariyanto ${ }^{1}$, Anid Supriyadi ${ }^{1}$, I Dewa Gede Jaya Negara ${ }^{1}$ \\ ${ }^{1}$ Teknik Sipil/Fakultas Teknik, Universitas Mataram \\ Jl. Majapahit no 62, Mataram, Indonesia \\ *Email: h.saidah@unram.ac.id
}

\begin{abstract}
Abstrak
Kawasan lindung kota adalah Kawasan yang berfungsi melindungi kelestarian lingkungan hidup dan sumber daya di dalamnya. Pemerintah Kota Mataram telah menetapkan tiga kelurahan yakni Selagalas, Pagutan Timur dan Sayang-sayang sebagai kawasan lindung Kota Mataram. Penelitian ini melakukan pengujian terhadap kemampuan resapan ketiga kawasan lindung tersebut untuk mengukur kinerja ketiganya dalam menjaga tata air sekaligus mencegah kerusakan lingkungan akibat peristiwa alam di wilayah Kota Mataram. Penelitian dilakukan dengan mengukur kemampuan penyerapan air (infiltrasi) di ketiga kelurahan tersebut menggunakan double ring infiltrometer serta menguji sifat fisik tanah di laboratorium. Hasil yang diperoleh adalah bahwa kapasitas infiltrasi kelurahan Selagalas, Pagutan Timur dan sayang-sayang berturut-turut adalah $2.8 \mathrm{~cm} / \mathrm{jam}, 2.2 \mathrm{~cm} / \mathrm{jam}$ dan $1.8 \mathrm{~cm} / \mathrm{jam}$, dengan jenis tanah yang hampir sama yaitu lempung berpasir. Berdasarkan angka laju resapan menunjukkan bahwa laju penyerapan Pagutan Timur dan Selagalas masuk kategori sedang dan Sayang sayang berkategori sedang lambat. Dengan curah hujan rerata harian antara $12-43 \mathrm{~mm} / \mathrm{hari}$, maka potensi penyerapan air rerata dari ketiga lokasi adalah $124.936 \mathrm{~m}^{3} /$ tahun untuk Kelurahan Pagutan Timur, Kelurahan Selagalas $284.963 \mathrm{~m}^{3} /$ tahun dan Sayang sayang $165.311 \mathrm{~m}^{3} /$ tahun. Namun angka potensi ini masih memerlukan penyesuaian mengingat ketiga kelurahan tersebut sudah banyak beralih fungsi menjadi pemukiman
\end{abstract}

Kata kunci: infiltrasi; Kawasan lindung; potensi penyerapan air

\begin{abstract}
Urban protected areas are functioned to protect the environment and its resources. The Mataram City Government has designated three sub-districts, namely Selagalas, East Pagutan and Sayang-Sayang as protected areas for the City of Mataram. This study tested the infiltration capacities of the protected areas to measure their performance in maintaining water management and preventing environmental damage due to natural hazards in Mataram City. The research was conducted by measuring the infiltration rate using a double ring infiltrometer and testing the physical properties of the soil in the laboratory. The results obtained that the infiltration capacity of Selagalas, East Pagutan and Sayang Sayang subdistricts are $2.8 \mathrm{~cm} / \mathrm{hour}, 2.2 \mathrm{~cm} / \mathrm{hour}$ and $1.8 \mathrm{~cm} / \mathrm{hour}$, respectively. The laboratory test for identifying the soil type shown that all of the sample of soils are sandy loam. Based on the infiltration rate, it shows that the infiltration rate of Pagutan Timur and Selagalas are in the medium category and Sayang Sayang is in the slow category. The daily average of Mataram area rainfall is between $12-43 \mathrm{~mm} /$ day, and the average of water infiltration potential is $124,936 \mathrm{~m}^{3} /$ year for East Pagutan, then Selagalas and Sayang sayang is $284,963 \mathrm{~m}^{3} /$ year and $165,311 \mathrm{~m}^{3} / y e a r$ respectively. However, this potential figure still requires adjustments since the protected areas have changed their function into settlements.
\end{abstract}

Keywords: infiltration, protected area, water absorption potential

\section{Pendahuluan}

Pesatnya laju pembangunan yang mengiringi peningkatan jumlah penduduk di Kota Mataram telah berimplikasi pada semakin banyaknya perubahan fungsi lahan akibat tingginya kebutuhan perumahan bagi masyarakat. Pemerintah Kota Mataram telah menetapkan pola tata ruang wilayah sebagaimana tertuang dalam RPJMD (Rencana Pembangunan Jangka Menengan Daerah) 2016-2021 untuk berbagai peruntukannya (Pemerintah Kota Mataram, 2016).
Dalam penetapan RPJMD sebelumnya (tahun 20112015), ditetapkan 3 kelurahan sebagai kawasan lindung yaitu kelurahan Selagalas, Sayang-sayang dan Pagutan Timur. Namun dalam RPJMD yang baru (tahun 2016-2021), penetapan Kawasan lindung itu berubah menjadi 18 kelurahan yang menjalankan fungsi sebagai Kawasan yang memberikan perlindungan terhadap Kawasan di bawahnya, diantaranya adalah kelurahan Bintaro, Taman Sari, Ampenen Selatan, Ampenan Utara, Pejeruk, Kebon Sari, Rembiga, Karang Baru, Monjok, Monjok Barat, Mataram Timur, Cakranegara Timur, Cakranegara 
Selatan Baru, Tanjung Karang, Jempong Baru, Dasan Cermen, Sayang-sayang dan Selagalas.

RPJMD Kota Mataram menyebutkan bahwa kawasan Lindung adalah wilayah yang ditetapkan dengan fungsi utama untuk melindungi kelestarian lingkungan hidup yang mencakup sumber daya alam dan sumber daya buatan (Pemerintah Kota Mataram, 2016).

Sebagai lokasi yang telah ditetapkan sebagai Kawasan lindung, lokasi ini berperan sebagai Kawasan yang melindungi kelestarian tanah dan air, sebagai area peresapan air untuk keperluan konservasi air, penyediaan air, dan penanggulangan banjir baik untuk Kawasan tersebut maupun Kawasan di bawahnya.

Konservasi dalam Kamus Besar Indonesia didefinisikan sebagai pemeliharaan dan perlindungan secara teratur untuk mencegah kerusakan dan kemusnahan dengan jalan mengawetkan atau pengawetan. Konservasi adalah usaha yang dilakukan agar sumber daya yang dibutuhkan untuk kehidupan itu tetap mampu melayani kebutuhan hidup manusia, tidak rusak/cepat habis terpakai (Prawiro, 1988).

Penelitian ini berfokus pada pengujian kemampuan resapan dari ketiga kelurahan yang telah ditetapkan sebagai kawasan lindung tersebut. Hal ini sebagai bentuk evaluasi dari penetapan kawasan tersebut sebagai kawasan resapan air sekaligus untuk mengetahui potensi peresapan dari air hujan.

Hal ini dilakukan mengingat pada umumnya rencana tata ruang suatu wilayah cenderung hanya mengacu pada kebutuhan ruang serta nilai ekonomis sehingga tak jarang mengesampingkan nilai ekologisnya. Akibat dari kecenderungan itu banyak suatu daerah yang telah menetapkan rencana tata ruang untuk kawasan budidaya (misal untuk kawasan industri, Kawasan wisata), sedangkan rencana tata ruang untuk Kawasan lindung terabaikan (Wibowo, 2006).

Kemampuan peresapan suatu daerah ditentukan oleh angka laju infiltrasi, dimana diartikan sebagai proses meresapnya air dari permukaan tanah ke dalam lapisan tanah. Infiltrasi merupakan bagian dari siklus hidrologi yang memegang peranan penting sebagai penyedia air bawah permukaan, pengendali banjir, dan membuat distribusi air di alam lebih merata antara musim hujan dan kemarau.

Infiltrasi adalah komponen penting dalam mengisi kelengasan tanah dan air tanah. Pengisian Kembali lengas tanah sama dengan delta antara nilai infiltrasi dan perkolasi jika ada. Pengisian kembali air tanah sama dengan jumlah air yang terperkolasi dikurangi kenaikan air kapiler (jika ada). Air perkolasi ini akan mengisi air tanah dan menentukan besarnya aliran dasar di sungai (Wibowo, 2006).

Karena pada dasarnya masalah konservasi tanah adalah hubungan antara intensitas hujan, kapasitas infiltrasi dan aliran permukaan. Kapasitas infiltrasi merupakan laju maksimal kemampuan peresapan air ke dalam tanah pada suatu saat.

Penentuan suatu kawasan dalam tata ruang kota harus ditetapkan melalui studi yang memadai, termasuk di dalamnya peruntukan suatu lokasi sebagai kawasan lindung. Karena begitu pentingnya fungsi kawasan ini bagi konservasi dan perlindungan tata air untuk daerah yang ada di bawahnya.

\section{Metode Penelitian}

\section{Lokasi Penelitian}

Kota Mataram dengan luas wilayah $61,30 \mathrm{~km}^{2}(6.130$ Ha). Secara geografis Kota Mataram terletak pada posisi $116^{\circ} 04^{\prime}-116^{\circ} 10^{\prime} \mathrm{BT}$, dan $08^{\circ} 33^{\prime}-08^{\circ} 38^{\prime}$ LS. Wilayah Kota Mataram merupakan dataran rendah dan sedang, dan sebagian lain berada pada ketinggian 50 meter di atas permukaan laut (mdpl).

Penelitian ini dilakukan di Kota Mataram (Gambar 1), tepatnya di tiga kelurahan yang pada tahun 2011 ditetapkan sebagai Kawasan lindung, yaitu Kelurahan Selagalas $\left(2.99 \mathrm{~km}^{2}\right)$ yang ada di kecamatan Sandubaya, kelurahan Pagutan Timur $\left(1.03 \mathrm{~km}^{2}\right) \mathrm{di}$ kecamatan Mataram dan Kelurahan Sayang-sayang $\left(2.12 \mathrm{~km}^{2}\right)$ di kecamatan Cakranegara. Pengukuran infiltrasi dilakukan sebanyak 3 titik pada masingmasing lokasi.

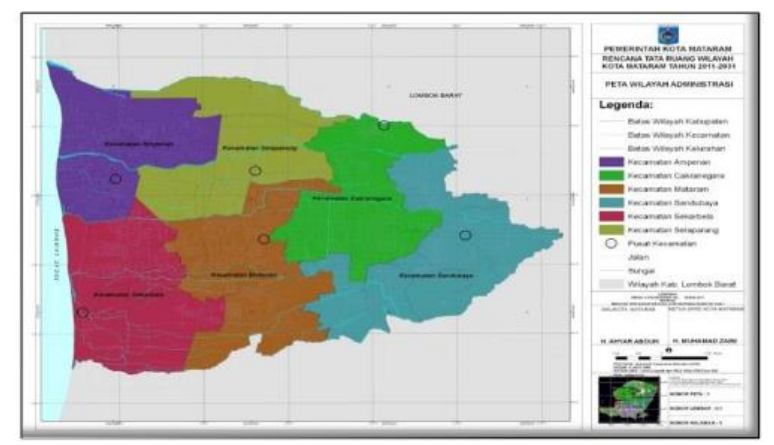

Gambar 1. Wilayah Kota Mataram Sumber : Pemerintah Kota Mataram, 2011

\section{Tahapan Penelitian}

Penelitian dilakukan dengan cara melakukan pengujian infiltrasi secara langsung di lapangan, untuk mendapatkan besaran laju infiltrasi. Alat yang digunakan adalah double ring infiltrometer (infiltrometer cincin ganda). Selain mengukur infiltrasi langsung, dilakukan juga penentuan jenis tanah melalui uji di laboratorium.

Hasil pengukuran infiltrasi selain untuk mengetahui karakteristik laju infiltrasi juga dapat menentukan kapasitas infiltrasi dimana kapasitas infiltrasi ini akan 
sangat diwarnai oleh jenis tanah di lokasi pengukuran. Penentuan jenis tanah dilakukan dengan metode USDA (United States of Department Agriculture), menggunakan hasil pengujian kadar air, spesifik gravity, angka pori, porositas dan bulk density.

Analisis potensi resapan dihitung menggunakan persamaan kapasitas resapan menggunakan data hujan dari tiga stasiun hujan yang ada di sekitar Mataram, yaitu stasiun Ampenan, Selaparang dan Cakranegara. Curah hujan rerata daerah dihitung dengan metode rata-rata aljabar.

Langkah penyelesaian penelitian selanjutnya disajikan pada gambar 2 .

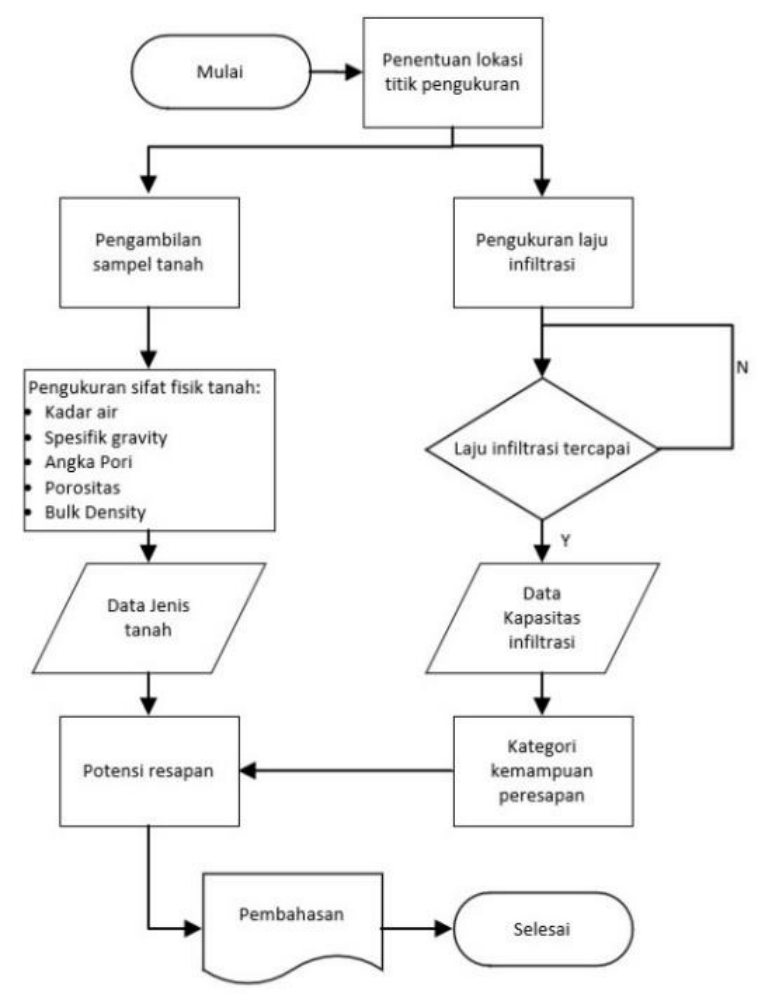

Gambar 2. Bagan alur penelitian

\section{Hasil dan Pembahasan}

\section{Pengukuran Infiltrasi}

Pengukuran infiltrasi digunakan untuk mengetahui setidaknya dua parameter penting yaitu laju infiltrasi dan kapasitas infiltrasi. Laju infiltrasi diartikan sebagai banyaknya air yang masuk ke tanah per satuan waktu. Sedangkan kapasitas infiltrasi adalah laju maksimum air yang dapat masuk ke dalam tanah. Laju maksimum ini ditunjukkan ketika laju peresapan telah mencapai angka yang konstan (Triatmodjo, 2009).

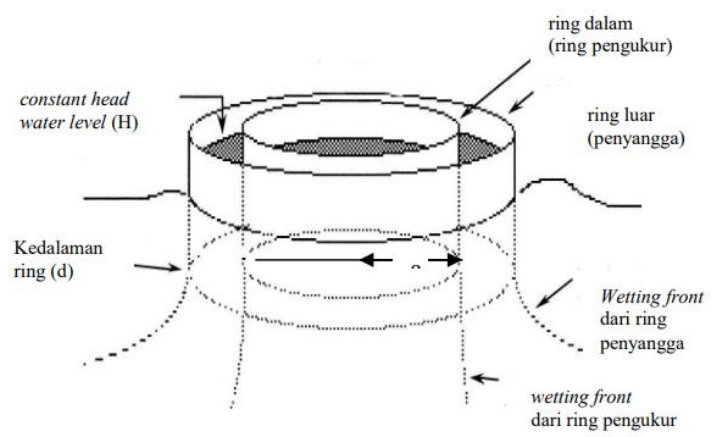

Gambar 3. Double ring infiltrometer Sumber: Dariah \& Rachman, 2006

Saputra (2013) melakukan pengujian infiltrasi di tiga kelurahan yang menjadi Kawasan lindung Kota Mataram. Berikut ini hasil pengujian infiltrasi yang diperoleh dengan menggunakan double ring infiltrometer pada kelurahan Selagalas (Tabel 1 dan gambar 3) dan rekapitulasi untuk seluruh titik lokasi pengukuran disajikan pada Tabel 2.

Tabel 1 Hasil Pengujian Infiltrasi di Kelurahan Selagalas

\begin{tabular}{lllll}
\hline \multicolumn{1}{c}{ Jam } & $\mathrm{t}(\mathrm{mnt})$ & $\mathrm{t}(\mathrm{mnt})$ & $\mathrm{h}(\mathrm{cm})$ & $\mathrm{f}(\mathrm{cm} / \mathrm{jam})$ \\
\hline 9.57 & 0 & & & \\
10.02 & 5 & 5 & 3.7 & 44.4 \\
10.07 & 10 & 5 & 2.3 & 27.6 \\
10.12 & 15 & 5 & 1.7 & 20.4 \\
10.17 & 20 & 5 & 1.3 & 15.6 \\
10.22 & 25 & 5 & 1 & 12 \\
10.27 & 30 & 5 & 0.8 & 9.6 \\
10.32 & 35 & 5 & 0.6 & 7.2 \\
10.42 & 40 & 5 & 0.6 & 7.2 \\
10.52 & 50 & 10 & 1.1 & 6.6 \\
11.02 & 60 & 10 & 0.9 & 5.4 \\
11.12 & 70 & 10 & 0.5 & 3 \\
\hline
\end{tabular}

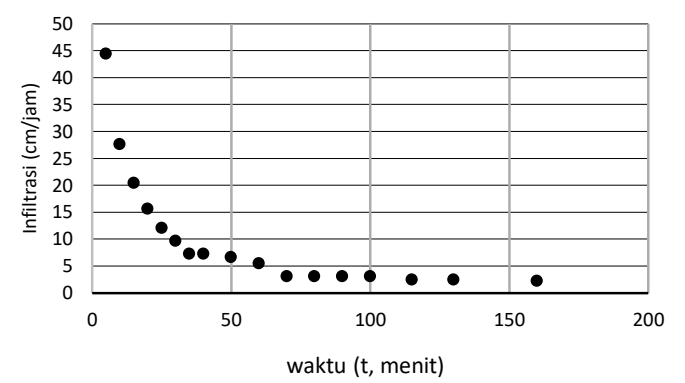

Gambar 4. Kurva laju infiltrasi pada titik di kelurahan Selagalas

Tabel 2 Rekapitulasi hasil pengukuran infiltrasi

\begin{tabular}{lccccccccc}
\hline \multicolumn{3}{c}{ Pagutan Timur } & \multicolumn{3}{c}{ Selagalas } & \multicolumn{3}{c}{ Sayang-sayang } \\
\hline & PT1 & PT2 & PT3 & SG1 & SG2 & SG3 & SS1 & SS2 & SS3 \\
\hline 0 & & & & & & & & & \\
5 & 18.0 & 48.0 & 49.2 & 44.4 & 15.6 & 25.2 & 26.4 & 19.2 & 28.8 \\
10 & 14.4 & 34.8 & 37.2 & 27.6 & 12.0 & 20.4 & 21.6 & 15.6 & 22.8 \\
15 & 9.6 & 28.8 & 31.2 & 20.4 & 9.6 & 16.8 & 18.0 & 10.8 & 18.0 \\
20 & 7.2 & 24.0 & 26.4 & 15.6 & 8.4 & 15.6 & 15.6 & 7.2 & 15.6 \\
25 & 4.8 & 19.2 & 21.6 & 12.0 & 6.0 & 13.2 & 10.8 & 6.0 & 13.2 \\
30 & 3.6 & 14.4 & 19.2 & 9.6 & 4.8 & 12.0 & 8.4 & 3.6 & 9.6 \\
35 & 2.4 & 13.2 & 15.6 & 7.2 & 3.6 & 9.6 & 4.8 & 3.6 & 7.2 \\
40 & 1.2 & 13.2 & 12.0 & 7.2 & 2.4 & 8.4 & 2.4 & 2.4 & 6.0
\end{tabular}




\begin{tabular}{|c|c|c|c|c|c|c|c|c|c|}
\hline & \multicolumn{3}{|c|}{ Pagutan Timur } & \multicolumn{3}{|c|}{ Selagalas } & \multicolumn{3}{|c|}{ Sayang-sayang } \\
\hline & PT1 & PT2 & PT3 & SG1 & SG2 & SG3 & SS1 & SS2 & SS3 \\
\hline$\overline{50}$ & 0.6 & 11.4 & 8.4 & 6.6 & 1.8 & 6.0 & 1.8 & 1.8 & 5.4 \\
\hline 60 & 0.6 & 9.0 & 4.8 & 5.4 & 1.8 & 5.4 & 1.2 & 1.8 & 3.6 \\
\hline 70 & 0.6 & 6.0 & 3.0 & 3.0 & 1.8 & 4.2 & 1.2 & 1.8 & 2.4 \\
\hline 80 & & 4.2 & 3.0 & 3.0 & & 3.0 & 1.2 & & 2.4 \\
\hline 90 & & 4.2 & 3.0 & 3.0 & & 3.0 & & & 2.4 \\
\hline 100 & & 4.2 & 3.0 & 3.0 & & 3.0 & & & 2.4 \\
\hline 115 & & & 2.8 & 2.4 & & 2.8 & & & \\
\hline 130 & & & & 2.4 & & 2.0 & & & \\
\hline 160 & & & & 2.2 & & & & & \\
\hline
\end{tabular}

Pelaksanaan pengukuran infiltrasi ini mengambil lokasi di tanah terbuka dan di kebun, serta pada saat siang hari di musim kemarau, dan saat cuaca cerah. Hasil pengujian infiltrasi pada tabel 2 memperlihatkan laju infiltrasi yang besar pada awal waktu, dan terus menurun secara eksponensial seiring pertambahan waktu. Hal ini normal dalam pengujian infiltrasi karena laju infiltrasi di awal masih dipengaruhi oleh banyak faktor terutama indeks kekeringan tanah, namun seiring dengan lamanya proses infiltrasi berjalan dan tanah menjadi semakin jenuh laju infiltrasi akan semakin menurun sehingga mencapai konstan pada suatu waktu tertentu. Laju infiltrasi yang konstan inilah yang menggambarkan kemampuan kapasitas tanah yang sebenarnya dalam menyerap air karena sudah tidak ada lagi pengaruh kekeringan tanah, dan murni hanya dipengaruhi oleh sifat fisik tanah.

Dari hasil pengukuran yang dilakukan dapat ditarik angka rerata kapasitas infiltrasi dari ketiga lokasi, yaitu Pagutan Timur sebesar $2.6 \mathrm{~cm} / \mathrm{jam}$, Selagalas sebesar 2,8 cm/jam dan Sayang sayang sebesar 1.8 $\mathrm{cm} /$ jam. Hasil pengukuran kapasitas infiltrasi tersebut kemudian diklasifikasikan menurut tabel 3.

Tabel 3. Klasifikasi Laju Infiltrasi

\begin{tabular}{lc}
\hline Kelas & $\begin{array}{c}\text { Laju infiltrasi konstan } \\
(\mathrm{mm} / \mathrm{jam})\end{array}$ \\
\hline Sangat lambat & $<1$ \\
Lambat & $1-5$ \\
Sedang lambat & $5-20$ \\
Sedang & $20-65$ \\
Sedang cepat & $65-125$ \\
Cepat & $125-250$ \\
Sangat cepat & $>250$ \\
\hline \multicolumn{2}{c}{ Sumber: Unland \& O'Neal, 1951}
\end{tabular}

Berdasarkan tabel klasifikasi laju infiltrasi menurut Uhland dan O’Neil, dapat disimpulkan bahwa laju infiltrasi lokasi Selagalas dan Pagutan Timur berada pada kategori sedang sedangkan pada lokasi Sayang sayang berkategori sedang lambat.

Dalam hal penentuan lokasi ketiga lokasi tersebut sebagai kawasan lindung dimana fungsi utamanya adalah menjaga tata air di kawasan yang dilindungi di bawahnya, maka sebenarnya jika dilihat dari kemampuan laju infiltrasi, pemilihan ketiga lokasi tersebut masih tergolong kurang tepat, karena berada pada klasifikasi kecepatan sedang dan sedang lambat. Sehingga jika memungkinkan masih perlu dilakukan pengujian yang lebih detail terkait penentuan kawasan lindung ini agar kawasan terpilih dapat melaksanakan fungsinya secara maksimal.

\section{Pengujian Sifat Fisik Tanah}

Pengujian sifat fisik tanah dimaksudkan untuk mengetahui beberapa parameter fisik tanah untuk digunakan dalam menentukan jenis tanah. Sampel tanah diambil pada lokasi dimana lokasi tersebut dilakukan pengukuran infiltrasi.

Pengujian dilakukan di laboratorium Geoteknik dan geodesi Fakultas Teknik untuk mengukur parameter kadar Air, berat jenis, angka pori, porositas dan bulk density. Hasil yang diperoleh kemudian diolah menggunakan metode USDA (United States of Department Agricultural) untuk menentukan jenis tanah.

Hasil analisis klasifikasi tanah yang diperoleh memperlihatkan bahwa jenis tanah yang ada di ketiga kawasan lindung tersebut memiliki jenis tanah yang hampir sama, yaitu didominasi jenis lempung berpasir dan sedikit bagian berjenis lempung.

\section{Potensi Resapan}

Analisis potensi resapan ketiga lokasi kawasan lindung dilakukan menggunakan data hujan rerata harian dari 3 stasiun hujan yang ada di Mataram yaitu stasiun Selaparang, stasiun Ampenan dan stasiun Cakranegara dengan Panjang data 10 tahun. Dari analisis data hujan diperoleh hujan rerata daerah harian yang merupakan perataan dari ketiga stasiun tersebut berkisar antara $12 \mathrm{~mm} /$ hari hingga 43 $\mathrm{mm} / \mathrm{hari}$.

Dalam analisis resapan, perhitungan potensi kapasitas resapan didasarkan pada selisih antara distribusi hujan dengan besaran infiltrasi pada masing-masing diskritisasi waktu. Data hujan harian terlebih dahulu didistribusikan ke dalam hujan berdurasi pendek mengikuti durasi pencatatan infiltrasi menggunakan metode Mononobe, sehingga dapat dihitung selisih keduanya dan dihitung resapan yang dihasilkan.

Perhitungan potensi resapan dilakukan menggunakan persamaan berikut (Iwaco \& Waseco, 1990):

$\mathrm{R}=\mathrm{A} \times \mathrm{P} \times \mathrm{C}$.

\section{Dimana:}

$\mathrm{R}=$ laju resapan air tanah tahunan $\left(\mathrm{m}^{3} / \mathrm{th}\right)$;

$\mathrm{A}=$ Luas daerah tangkapan (m2);

$\mathrm{P}=$ curah hujan tahunan $(\mathrm{mm})$; dan

$\mathrm{C}=$ koefisien resapan $(\%)$

Koefisien resapan didefinisikan sebagai banyaknya volume curah hujan terinfiltrasi dibandingkan volume hujan total. Persamaan yang biasa digunakan untuk menghitung koefisien resapan adalah

$\mathrm{C}=(\mathrm{I} x H) / P$ 
Dimana:

$\mathrm{H}=$ jumlah hari hujan dalam setahun

$\mathrm{I}=$ laju infiltrasi $(\mathrm{cm} / \mathrm{jam})$

Berdasarkan perhitungan yang dilakukan, maka kelurahan Pagutan Timur memiliki potensi resapan sebesar $124.936 \mathrm{~m}^{3} /$ tahun, kelurahan Selagalas sebesar $284.963 \mathrm{~m}^{3} /$ tahun, sedangkan kelurahan Sayang sayang memiliki potensi resapan sebesar $165.311 \mathrm{~m}^{3} /$ tahun.

Namun begitu, angka potensi resapan ini masih merupakan perkiraan yang terlalu kasar, dimana dalam perhitungannya dianggap seluruh luas kelurahan merupakan tanah kebun, serupa dengan lokasi dimana dilakukan pengukuran infiltrasi. Padahal dalam kenyataannya ketiga kelurahan yang dipilih menjadi Kawasan lindung tersebut telah sangat padat dibangun pemukiman.

Perhitungan angka potensi resapan yang aktual sebenarnya harus dihitung berdasarkan tata guna lahan yang ada. Sehingga hasil perhitungan potensi kemampuan resapan yang diperoleh adalah murni didapat dari daerah yang benar-benar mampu meresapkan air hujan.

\section{Kesimpulan dan Saran}

\section{Kesimpulan}

Kesimpulan yang dapat ditarik dari penelitian ini adalah :

1. Pemilihan tiga kelurahan diantaranya Pagutan Timur, Selagalas dan Sayang sayang untuk menjadi kawasan lindung bagi Kota Mataram adalah cukup baik jika ditinjau dari data teknis ketiga lokasi. Dimana kelurahan Pagutan Timur dan Selagalas memiliki kemampuan peresapan dengan kategori sedang dan sedangkan Sayang sayang memiliki kemampuan peresapan sedang lambat.

2. Jenis tanah dari ketiga kelurahan tersebut adalah sama yaitu lempung berpasir. Sedangkan potensi peresapan yang dimiliki ketiganya bervariasi mengikuti luas dan angka kapasitas infiltrasinya. Kelurahan Selagalas memiliki potensi peresapan terbanyak, disusul Sayang sayang dan Pagutan Timur.

\section{Saran}

Penelitian ini hanya menghitung potensi resapan dari luas daerahnya secara keseluruhan, tanpa melihat tata guna lahannya. Sedangkan potensi resapan sangat erat kaitannya dengan fungsi lahan. Sehingga disarankan pada peneliti berikutnya dalam memperhitungkan potensi resapan dapat menggunakan data tata guna lahan apalagi untuk daerah yang sudah nyata beralih fungsi menjadi daerah pemukiman.

\section{Daftar Pustaka}

Dariah, A., \& Rachman, A. (2006). Pengukuran Infiltrasi: Sifat Fisik Tanah dan Metode Analisisnya. Balai Besar Litbang Sumberdaya Lahan Pertanian.

Iwaco, \& Waseco. (1990). West Java Provincial Water Sources Master Plan for Water Supply - Volume A: Groundwater Resources [Project Report of Cooperative Work between The Government of Indonesia and The Government of Netherlands.].

Pemerintah Kota Mataram. (2011). Peraturan Daerah Kota Mataram Nomor 12 Tahun 2011 Tentang Rencana Tata Ruang Wilayah Kota.

Pemerintah Kota Mataram. (2016). Rencana Pembangunan Jangka Menengah Daerah (RPJMD) Kota Mataram Tahun 2016-2021.

Prawiro, R. H. (1988). Ekologi Lingkungan Pencemaran (4th ed.). Satya Wacana.

Saputra, L. A. T. (2013). Analisa Potensi Resapan Air Hujan di Kawasan Lindung Kota Mataram. Universitas Mataram.

Triatmodjo, B. (2009). Hidrologi Terapan. Beta Offset.

Wibowo, M. (2006). Model Penentuan Kawasan Resapan Air Untuk Perencanaan Tata Ruang Berwawasan Lingkungan. Jurnal Hidrosfir, 1(1). 